\title{
Experimental Study of the Koppers-Hinckley-Podbiel- niak Apparatus and Method for the Determination of Conjugated Dienes
}

\author{
By Martin Shepherd, Richard Thomas, Shuford Schuhmann, and Vernon Dibeler
}

\begin{abstract}
There is reported an experimental study of the accuracy, reproducibility, and general operating characteristics of the Koppers-Hinckley-Podbielniak apparatus and Analytical Method L. M. 2.1.1.7 (or 2.1.1.9) of the Office of Rubber Reserve for the determination of conjugated dienes in hydrocarbon mixtures. Physical equilibria and physico-chemical behavior of the analytical system are discussed, accuracy and reproducibility are evaluated, and certain operating precautions are given.
\end{abstract}

\section{INTRODUCTION}

The experimental study of the KoppersHinckley-Podbielniak apparatus and Analytical Method L. M. 2.1.1.7 (or 2.1.1.9) of the Office of Rubber Reserve (hereinafter designated RuR) was conducted early in 1945, and most of the information obtained was submitted for discussion on February 15 and 16, 1945, at Meeting No. 9 of the Committee on Butadiene Specification and Methods of Analysis, Office of Rubber Reserve, and released in the minutes of that meeting, pages 23 to 48 .

Since this time additional information has been obtained, and a practical estimation of the usefulness of the apparatus and the degree of reliability of the method has been made. This estimation is given essentially in the condensed conclusions, placed ahead of the account of the experiments to serve readers whose time and interest may be limited.

The original and the additional observations are collected here for the convenient reference of those who use this apparatus and method, or depend upon its results. The method itself was designed for the determination of 1-3 butadiene in specification grades of this substance used for the manufacturing of synthetic rubber. It is based upon the rapid and quantitative absorption of conjugated dienes in molten maleic anhydride at approxi- mately $100^{\circ} \mathrm{C}$. The other constituents of the sample that dissolve abundantly in the maleic reagent are freed from physical solution by displacement with a stream of air-free carbon dioxide. The volumes of the initial sample and of the residue are compared to establish the total impurity, and the balance is reported as conjugated dienes, or, if knowledge of the sample permits, as 1-3 butadiene.

\section{Condensed Conclusions}

The practical conclusion reached after an experimental study of the Koppers-Hinckley-Podbielniak apparatus and RuR method L. M. 2.1.1.7 (or 2.1.1.9) is essentially this: The apparatus and method give satisfactory results for the determination of 1,3-butadiene in specificationgrade butadiene, but results obtained with mixtures of lesser purity are not always satisfactory.

This conclusion may be further qualified by stating the obvious fact that the determination of 1,3-butadiene will not be satisfactory in the case of mixtures containing significant amounts of $\mathrm{C}_{5}$ or $\mathrm{C}_{8}$ hydrocarbons until an adequate method for the determination and possibly the removal of the interfering compounds has been developed. Only then can a satisfactory correction be made for their presence, and without this correction the determination of butadiene carries with it the 
uncertainty attached to the determination of the interfering heavier compounds.

The conclusion stated in the first paragraph is in no disagreement with the claims of Hinckley, who has repeatedly stated that the apparatus was intended for the determination of conjugated dienes in specification-grade butadiene. The application of the apparatus and method to mixtures of lesser purity was obviously intended by the Office of Rubber Reserve, however, since the burette supplied is capable of measuring 110 percent of impurity in the sample, and the stated scope of the method RuR (L. M. 2.1.1.7 or L. M. 2. 1.1.9), includes "recycle-grade butadiene" and "butadiene in any concentration in $\mathrm{C}_{4}$ and lighter mixtures." The desire to extend the scope of the method to samples of purity less than specification grade has complicated the analytical picture, and the extent of this complication may be about as follows:

1. In the approximate range 95 to 85 percent butadiene, reproducibilities ranging from \pm 0.01 to \pm 0.4 percent of the whole sample have been observed under prescribed operating conditions. Larger variations have occasionally been observed. In this range agreement with the mass spectrometer may be as good as \pm 0.2 to \pm 0.4 percent, but greater variance has been observed.

2 . In the approximate range 15 to 2 percent butadiene, reproducibilities of about \pm 0.4 percent may be expected, but wider variations have been observed. Agreement within 2.0 percent of results obtained by the mass spectrometer may be expected.

From the practical viewpoint, these conclusions are important:

1. Several determinations of conjugated dienes in every sample must be made in order to establish the proper behavior of the apparatus with respect to reproducibility.

2. Samples of different composition cannot be run successively through the apparatus without upsetting equilibrium in the maleic absorber to an extent so great that the time lost in establishing the required new equilibrium is excessive. In the end, efficient operation of the analytical laboratory demands one apparatus for each kind of sample analyzed.

3. The Koppers-Hinckley-Podbielniak apparatus examined presented a serious health hazard by liberating harmful amounts of mercury vapor into the laboratory air. (The design has recently been modified in the attempt to eliminate this hazard. ${ }^{*}$ )

\section{General Plan of Experimental Study}

The general physico-chemical behavior of the absorption system was studied principally by means of analyses of inlet and outlet gases. These analyses were made by the mass spectrometer. For each of several mixtures of different compositions, reproducibility was measured in such a way that any change of composition on sampling was eliminated from the measurement. Accuracy was estimated by comparison with the mass spectrometer and the freezing point method.

Several modifications of the maleic reagent were studied. The effects of rate of flow, composition of reagent, and change of composition of samples were observed. General operating characteristics were noted, and some suggestions for modification of apparatus and procedure were derived.

\section{Physical Equilibria in the Koppers- Hinckley Apparatus}

In the volumetric determination of conjugated dienes by reaction with maleic anhydride or similar reagents, large errors may be caused by the solution of various constituents of the gas sample, which do not themselves react. The essential feature of the Hinckley apparatus is the provision for displacing dissolved gases from the reagent used to remove conjugated dienes. This displacement is effected by a stream of carbon dioxide (sufficiently air-free), which delivers the portion of the sample that does not react through a strong solution of potassium hydroxide to a burette where

\footnotetext{
* This report was prepared late in 1945. Since its preparation there have been advanced two variations of the methods here cited. One of these is the Shell-Torrance Modification that employs a second buret for the measurement of residue, as suggested in this report. The other modification is number 10 in the progression of the RuR L. M. 2.1.1. - Series. L. M. 2.1.1.10 employs a modified $\mathrm{CO}_{2}$ absorber and notes two changes of procedure: (1) Excess stopeock lubricant is removed by a benzene flush; (2) $40 \mathrm{ml}$ of fresh $\mathrm{KOH}$ is introduced at the top of the buret for measuring residues at the beginning of each analysis. Hinckley has offered a few observations to indicate that these changes have made it possible to attain a reproducibility of \pm 0.2 percent instead of the \pm 0.4 percent noted above. However, no such claim is made in the description of either of the two newer modifications of L. M. 2.1.1.7 or L. M.2.1.1.9. There is no change of sufficient significance in the modified physical-chemical picture offered by L. M.2.1.1.10 to tempt the prediction that a reproducibility of \pm 0.2 percent would be generally realized in the alternate analysis of samples of widely varying composition, without equilibration between analyses. Of the two modifications, that advanced by Shell-Torrance is based on sounder physical principles in regard to eliminating the error of a shifting saturation pressure with respect to water vapor in the residue, a matter discussed in the body of the present report.
} 
it is collected over the solution of potassium hydroxide.

The equilibria with respect to dissolved gases within this apparatus are accordingly pertinent aside from the chemical reaction, since they considerably determine not only the degree of accuracy achieved but also directly set the operating requirements with respect to obtaining necessary blanks - a very practical consideration from the viewpoint of total time required. Approximately, the following physical picture may be expected within the apparatus:

1. A fresh dose of maleic anhydride and a new charge of potassium hydroxide solution are poured into their allotted compartments. Carbon dioxide is th:n put through the apparatus until the entrained air is almost completely displaced and the residue shows an accumulation of gas over the potassium hydroxide no greater than $0.01 \mathrm{ml}$ per 30 minutes. At this time the condition of the two reagents is about as follows:

(a) The maleic anhydride is approximately saturated with respect to carbon dioxide and probably contains very little dissolved air.

(b) The potassium hydroxide solution contains dissolved air, which has not been displaced by the carbon dioxide. (Even when pure carbon dioxide is absorbed by a solution of potassium hydroxide, a residual minute bubble always remains following the complete absorption of $\mathrm{CO}_{2}$, providing the solution contains any dissolved air, which it always does unless the air has been carefully removed. This occurs because air is displaced to the gas phase during the absorption and eventual disappearance of the bubbles of $\mathrm{CO}_{2}$.)

2. Next a measured sample of the hydrocarbon mixture is pushed through the maleic anhydride by the continued stream of carbon dioxide, and the unreacted residue is in turn pushed through the $\mathrm{CO}_{2}$ absorber and collected over the potassium hydroxide in the burette. The residue is collected until its volume remains constant, which is the moment designated for its measurement. At this time, the condition of the two reagents is about as follows:

(a) The maleic anhydride contains some dissolved hydrocarbons that have not yet been completely displaced by the carbon dioxide, and the residue is correspondigly too small.

(b) The potassium hydroxide contains dissolved hydrocarbons, which in turn have displaced some air to the collected residue. Since the hydrocarbons are more soluble than air, the residue is too small by this difference. The potassium hydroxide is not yet in equilibrium with the hydrocarbons delivered as residue.

(c) The potassium hydroxide is mixed with pctassium carbonate, and the solution now has a different vapor pressure.

These conditions, given in (2a) and (2b) above, have been illustrated experimentally:

(2a) The presence of dissolved hydrocarbons in the maleic anhydride was shown as follows:

After 11 analyses of a sample containing about 15 percent of 1,3-butadiene, a blank was obtained by purging with $\mathrm{CO}_{2}$. This required about 7 hours. At the end of $3 \frac{1}{2}$ hours, $0.75 \mathrm{ml}$ of residue had been collected. The analysis of this residue by mass spectrometer was:

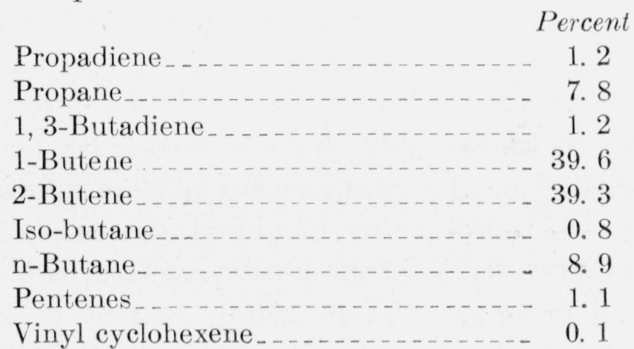

(2b) The fact that the potassium hydroxide solution dissolves notable amounts of the hydrocarbons composing the residue may be shown by collecting the residue and reading the volume with lapsing time. Here is an example:

\begin{tabular}{|c|c|}
\hline Time & $\begin{array}{l}\text { Volume of } \\
\text { residue }\end{array}$ \\
\hline & $m l$ \\
\hline $2: 39$ p. m & 0.00 \\
\hline $2: 54 \ldots \ldots$ & 3. 65 \\
\hline $2: 55 \ldots \ldots$ & 3. 64 \\
\hline $2: 56 \ldots$ & 2. 63 \\
\hline $2: 58 \ldots \ldots$ & 2. 62 \\
\hline $3: 00 \ldots$ & 3. 60 \\
\hline $3: 02 \ldots$ & 3.57 \\
\hline $3: 04 \ldots \ldots$ & 3.55 \\
\hline $3: 06 \ldots$ & 3.52 \\
\hline $3: 09$ & 3.51 \\
\hline $\begin{array}{l}8: 30 \text { a. m. (following } \\
\text { day) }\end{array}$ & 3.34 \\
\hline
\end{tabular}

This overnight reduction of volume is always noted. The immediate contraction after obtaining an apparent maximum is not always noted, but for the sake of reproducibility (and greater 
approach to accuracy) it appears important to capture the reading at its maximum.

The condition given in (2c) above introduces another error. The continual conversion of the potassium hydroxide to the carbonate, with a consequent increase of the saturation pressure of the solution, imposes the condition that no two gas volumes taken successively are comparable with respect to the pressure of water vapor. The measurement of the residue is converted (by means of a chart) for the change of the saturation pressure of the solution of potassium hydroxide with changing temperature; but this measurement still remains in error by an amount corresponding to the difference between the saturation pressure of the hydroxide and that of the varying mixtures of hydroxide and carbonate over which the residue is collected. This may amount to as much as 2 percent, depending upon volume of residue, concentration of carbonate, and temperature. The error may be corrected if the saturation pressures are known, but such a correction involves knowledge of the composition of the solution as well as the temperature. A similar case was studied in the Van Slyke Manometric Apparatus. ${ }^{1}$

Such an error is easily eliminated by designing the apparatus to permit measurement of the volumes to be compared in a separate burette where saturation with water alone is possible. ${ }^{2}$

A simple experiment illustrates the combined effect of the error of solubility of the gaseous residue in the confining liquid and the change of the saturation pressure of this liquid. Large residues were collected and measured, and thereafter portions $(1$ to $5 \mathrm{ml}$ ) of fresh potassium hydroxide solution were admitted through the top cock of the burette. The diminishing volumes of the residues are given below:

\begin{tabular}{|c|c|}
\hline $\begin{array}{c}\text { Residue before ad- } \\
\text { mitting fresh KOH } \\
\text { solution }\end{array}$ & $\begin{array}{c}\text { Residue after ad- } \\
\text { mitting fresh KOH } \\
\text { solution }\end{array}$ \\
\hline$m l$ & $m l$ \\
86.94 & 86.40 \\
86.20 & 86.04 \\
86.26 & 86.10 \\
86.40 & 86.14 \\
86.94 & 86.80 \\
\hline
\end{tabular}

1 Martin Shepherd, BS J. Research 12, 551 (1934) RP680.

${ }^{2}$ Martin Shepherd and E. O. Sperling, J. Research NBS 26, 341 (1941) RP1380.
The rate of obtaining essential equilibrium between hydrocarbon residue and the "potassium hydroxide solution" will depend upon the composition of the residue, degree and length of contact between residue and solution, temperature and composition of the solution, pressure of the residue, and such matters. A small amount of residue leaves a long column of solution relatively isolated in the burette; a large volume may nearly empty the burette and discharge the solution to the absorber where the mechanics of flow will speed the approach to equilibrium.

The effect of these partial equilibria may appear during the initial analyses with fresh maleic anhydride and fresh potassium hydroxide. Here is a series of analyses made under such conditions (Sample 43-3):

\begin{tabular}{|c|}
\hline Conjugated dienes \\
\hline Percent \\
15. 32 \\
14.60 \\
14.43 \\
14.46 \\
14.17 \\
13.95 \\
13.98 \\
\hline
\end{tabular}

The first residues were too small, because of the absorption of butenes and other hydrocarbons. The indicated purities were correspondingly high at first.

With the same maleic reagent, but fresh $\mathrm{KOH}$ solution, these results were next obtained:

\begin{tabular}{|c|}
\hline Conjugated dienes \\
\hline Percent \\
14. 81 \\
14.68 \\
14.54 \\
14.55 \\
14.53 \\
14.50 \\
\end{tabular}

Such behavior as this naturally causes errors when samples of differing composition are successively analyzed. The following examples illustrate what may be expected. The samples 
examined contained approximately 95,86 , and 15 percent conjugated dienes, and they were analyzed in succession as reported below:

Fresh maleic anhydride and potassium hydroxide solutions were put into the apparatus and the "blank with $\mathrm{CO}_{2}$ " was obtained as follows:

\begin{tabular}{|c|c|}
\hline Time elapsed & Residue \\
\hline Minutes & $m l$ \\
\hline $0 \ldots \ldots \ldots$ & 0. 22 \\
\hline $10 \ldots$ & 0.60 \\
\hline $40 \ldots$ & 1. 06 \\
\hline $70 \ldots$ & 1. 21 \\
\hline $90 \ldots$ & 1. 42 \\
\hline $110_{\ldots} \ldots$ & 1. 52 \\
\hline $130 \ldots$ & 1. 60 \\
\hline $150 \ldots$ & 1. 64 \\
\hline $170_{\ldots} \ldots$ & 1. 68 \\
\hline $190 \ldots$ & 1. 71 \\
\hline $210 \ldots$ & 1. 74 \\
\hline $250 \ldots$ & 1. 79 \\
\hline $270 \ldots \ldots$ & 1. 81 \\
\hline $290 \ldots$ & 1. 83 \\
\hline $310_{\ldots} \ldots$ & 1. 85 \\
\hline $340_{\ldots} \ldots \ldots$ & 1. 87 \\
\hline $370_{\ldots} \ldots$ & 1. 88 \\
\hline
\end{tabular}

Four analyses of sample $\mathrm{P}-6$ were made. These results were obtained:

\begin{tabular}{|c|}
\hline Conjugated dienes \\
\hline Percent \\
36.70 \\
86.31 \\
86.31 \\
86.29 \\
86.29 \\
\hline
\end{tabular}

2Probably a mistake.

Next, four analyses of Sample DDC-8R-379 were made, and the results were:

\begin{tabular}{|c|}
\hline Conjugated dienes \\
\hline Percent \\
96.10 \\
96.14 \\
96.18 \\
96.18 \\
\hline
\end{tabular}

This was followed by four analyses of Sample $\mathrm{P}-6$ :

\begin{tabular}{|c|}
\hline Conjugated dienes \\
\hline Percent \\
86.18 \\
86.11 \\
86.07 \\
86.09 \\
\hline
\end{tabular}

Next, six analyses of Sample 43-3 were performed:

\begin{tabular}{c} 
Conjugated dienes \\
\hline Percent \\
15. 74 \\
15. 38 \\
15. 68 \\
15. 33 \\
15.49 \\
15.11
\end{tabular}

With another change of maleic anhydride and potassium hydroxide, the following analyses were made in the order given:

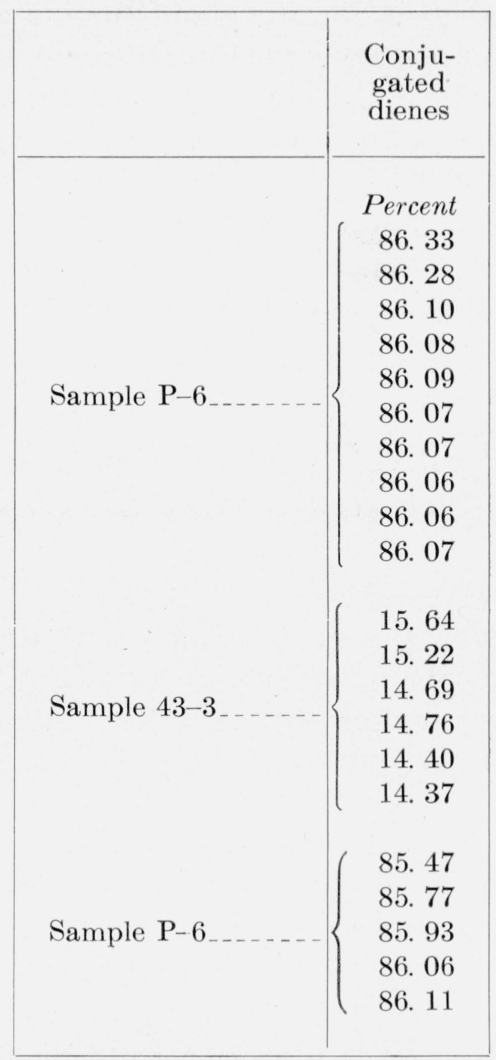


From the above analyses it will be noted that:

1. A change in composition of the sample makes it necessary to set up a new equilibrium in the reagents before reproducibility is attained.

2. If this change in composition is not great, two or three analyses may establish the required new equilibrium.

3. If the change in composition is considerable, five or more analyses may be required to set up the requisite new equilibrium.

4. In going from a sample of relative high purity to one of lower purity, the initial analyses of the second sample will indicate too high a purity. The reverse effect is obtained by proceeding in the opposite direction. This is a natural consequence of the changes in physical equilibria previously discussed.

5. Freedom from the error caused by a changing vapor pressure of water with a change of composition of the system $\mathrm{KOH}+\mathrm{K}_{2} \mathrm{CO}_{3}+\mathrm{H}_{2} \mathrm{O}$ is established in this experiment by the reproducibility attained at the end of each series of analyses, and the further fact that the final analyses of the second series of $\mathrm{P}-6$ yielded the same values as the final analyses of the the first series of analyses of this sample, whereas the apparent amount of conjugated diene would have progressively decreased in the second series had the vapor pressure of the absorbing solution been progressively rising by a significant amount. The change in vapor pressure, however, would in time have introduced a large error. The solution should never be used until expended, but rather discarded at about half its useful life.

\section{Physico-Chemical Equilibria in the Koppers-Hinckley Apparatus}

The net chemical and physical behavior of the absorption processes in the Hinckley apparatus may be conveniently studied through analyses of both the original sample and the residue after absorption. Such analyses may be made with the mass spectrometer. Since the volume of both sample and residue for the Hinckley analyses are known, the volume of each component present in both sample and residue may be computed from their analyses. These data indicate how much of each component was correctly or incorrectly retained in the maleic absorber and confining fluid and how much of each was correctly or incorrectly delivered to the residue. A balance sheet composed from these data discloses at a glance how matters stand and offers a basis for correcting the volumetric analysis on the assumption that the analyses of both residue and original sample by the mass spectrometer are correct.

In some of the cases examined, these two analyses appeared to be consistent in most respects, and the volumetric determination of conjugated dienes can be brought into satisfactory agreement with the original analysis of the sample by the mass spectrometer if corrected in the manner indicated by the balance sheet. In some cases, however, more of one component may appear in the residue than existed in the original sample. This embarrassing excess must have been generated or contributed by either the mass spectrometer or the Koppers-Hinckley apparatus (or both); and because the source of this excess is not positively known its presence must for the moment be termed a minor miracle. However, it is possible to explain the excessive amounts of these components if we assume that: 1. No chemical or physical process within the Hinckley apparatus yielded the excess product, and, 2. the mass spectrometer is capable of yielding a better analysis of the impurities in a sample of 1,3-butadiene if the impurities are concentrated in a residue and this residue is analyzed. Thus the interference offered by large amounts of 1,3-butadiene is eliminated.

The latter assumption is certainly straightforward. The soundness of the first assumption depends primarily on the physical behavior of the Hinckley absorbers. There are times when it is apparent that equilibrium has not been attained; but it is equally true that definite enough equilibrium can be established and maintained, and a long series of results obtained with separate portions of a single sample of uniform composition will assure this fact. At such times, the too abundant appearance of a component in the residue may indicate the need to correct the composition of the original sample as measured by the mass spectrometer, by means of the mass spectrometer's analysis of the residue. This assumes that the maleic reagent has itself made no contribution to the residue through chemical reaction; and this-assumption appears reasonable to organic chemists. 


\section{Equilibrium in the Analyses of Specification- grade Butadiene}

The use of specification-grade samples permits comparison with the results obtained by the freezing point method, and this furnishes more data for the estimation of the accuracy of the Koppers-Hinckley method as relates to this particular grade of sample. For this reason, and because the apparatus was specifically designed for the analysis of this particular grade of butadiene, these analyses have been selected to study the physico-chemical equilibrium by the use of the spectrometer.

In the case of the samples examined, the compounds present in excess were primarily butenes. It does not appear likely that these were manufactured in the Hinckley apparatus, and the physical equilibria were so well adjusted that no sudden surge of butanes can be suspected. The residues were taken for analysis by the mass spectrometer after a blank had been obtained and after five to eight analyses agreeing to \pm 0.01 percent had been made to establish satisfactory equilibrium in the Hinckley apparatus. Under these circumstances, the analyses of the residue by mass spectrometer would reasonably seem nearer to the true composition with respect to butenes than was the analysis of the original sample by mass spectrometer. If this is true, the mass spectrometer can be corrected by the mass spectrometer.

The data are tabulated in table 1 . Column 2 gives the analysis of the residue by mass spectrometer, and column 3 gives the corresponding volumes of each component computed from the known volume of the residue and its composition. Column 4 gives the amounts of each component in the original sample of $100 \mathrm{ml}$. (The values are the same as the mole percents reported by the mass spectrometer). Columns 5 and 6 give, respectively, the amounts of each component correctly and incorrectly retained by the maleic reagent. Amounts appearing in column 6, therefore, represent plus corrections to be made to the measured residue. Columns 7 and 8 give the amounts of each component that were present in the residue, again correctly and incorrectly; column 8, therefore, represents a list of minus corrections to be applied to the measured residue. Column 9 notes the amounts of any components found in the residue that were not in the original sample.

TABLE 1. Balance sheet showing amounts of each component before and after passing through the maleic absorber, according to the mass spectrometer

\begin{tabular}{|c|c|c|c|c|c|c|c|}
\hline \multirow{2}{*}{ Component } & \multirow{2}{*}{$\begin{array}{l}\text { Residue } \\
\text { from maleic } \\
\text { absorber }\end{array}$} & \multirow{2}{*}{$\begin{array}{l}\text { Vol- } \\
\text { ume } \\
\text { of } \\
\text { origi- } \\
\text { nal } \\
\text { sam- } \\
\text { ple }\end{array}$} & \multicolumn{2}{|c|}{$\begin{array}{l}\text { Volume re- } \\
\text { tained in } \\
\text { maleic } \\
\text { anhydride }\end{array}$} & \multicolumn{2}{|c|}{$\begin{array}{l}\text { Volume } \\
\text { discharged } \\
\text { to residue }\end{array}$} & \multirow{2}{*}{$\begin{array}{c}\text { Not } \\
\text { in } \\
\text { origi- } \\
\text { nal } \\
\text { sam- } \\
\text { ple } c\end{array}$} \\
\hline & & & $\begin{array}{l}\text { Cor- } \\
\text { rect- } \\
\text { ly }\end{array}$ & $\begin{array}{l}\text { Incor- } \\
\text { rect- } \\
\text { ly a }\end{array}$ & $\begin{array}{l}\text { Cor- } \\
\text { rect- } \\
\text { ly }\end{array}$ & $\begin{array}{l}\text { In- } \\
\text { cor- } \\
\text { rect- } \\
\text { ly b }\end{array}$ & \\
\hline
\end{tabular}

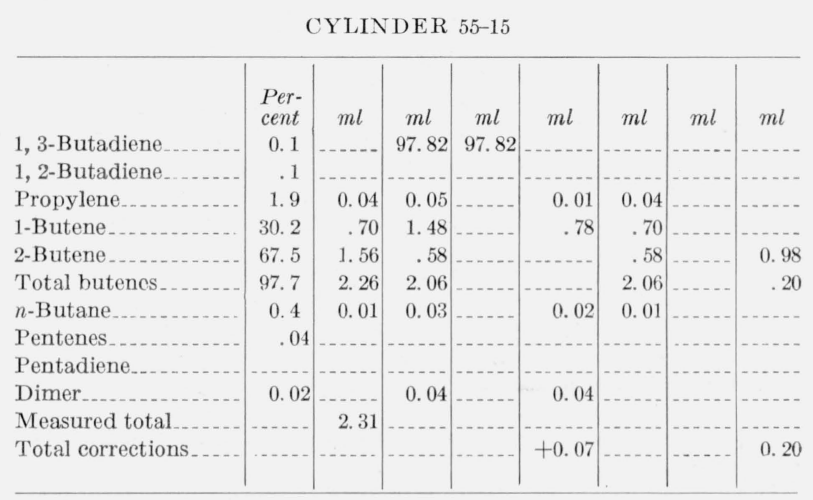

CYLINDER 5-14

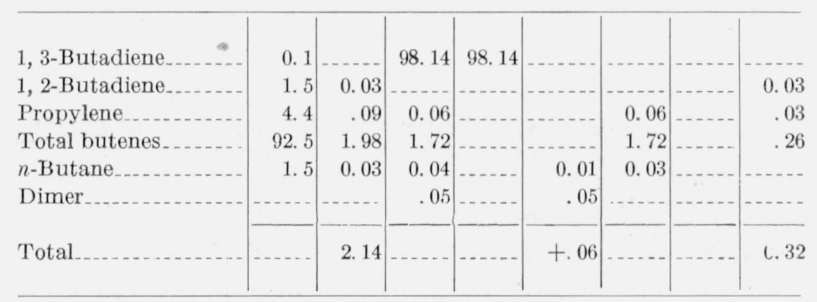

CYLINDER 11-20

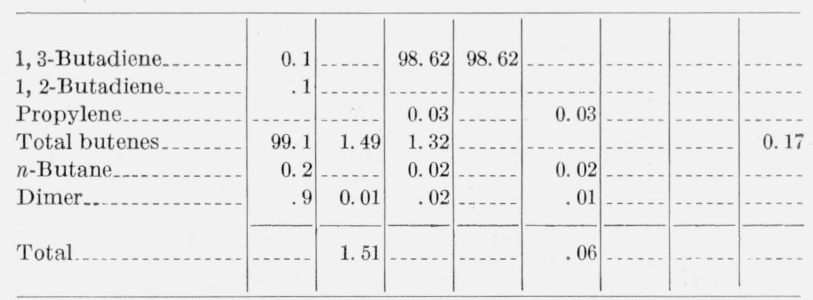

CYLINIDER 86-2 RuR-SR

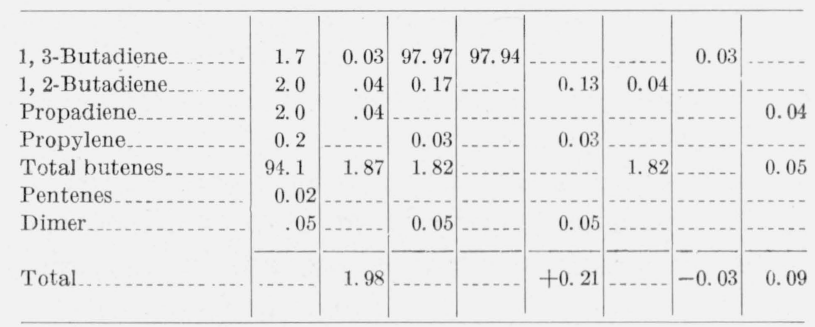

See footnotes at end of table. 
TABLE 1. Balance sheet showing amounts of each component before and after passing through the maleic absorber, according to the mass spectrometer--Continued.

\begin{tabular}{|c|c|c|c|c|c|c|c|}
\hline \multirow{2}{*}{ Component } & \multirow{2}{*}{$\begin{array}{c}\text { Residue } \\
\text { from maleic } \\
\text { absorber }\end{array}$} & \multirow{2}{*}{$\begin{array}{l}\text { Vol- } \\
\text { ume } \\
\text { of } \\
\text { origi- } \\
\text { nal } \\
\text { sam- } \\
\text { ple }\end{array}$} & \multicolumn{2}{|c|}{$\begin{array}{l}\text { Volume re- } \\
\text { tained in } \\
\text { maleic } \\
\text { anhydride }\end{array}$} & \multicolumn{2}{|c|}{$\begin{array}{l}\text { Volume } \\
\text { discharged } \\
\text { to residue }\end{array}$} & \multirow{2}{*}{$\begin{array}{c}\text { Not } \\
\text { in } \\
\text { origi- } \\
\text { nal } \\
\text { sam- } \\
\text { ple }{ }^{c}\end{array}$} \\
\hline & & & $\begin{array}{l}\text { Cor- } \\
\text { rect- } \\
\text { ly }\end{array}$ & $\begin{array}{l}\text { Incor- } \\
\text { rect- } \\
\text { ly a }\end{array}$ & $\begin{array}{l}\text { Cor- } \\
\text { rect- } \\
\text { ly }\end{array}$ & $\begin{array}{l}\text { In- } \\
\text { cor- } \\
\text { rect- } \\
\text { ly b }\end{array}$ & \\
\hline
\end{tabular}

CYLINDER $55-17$

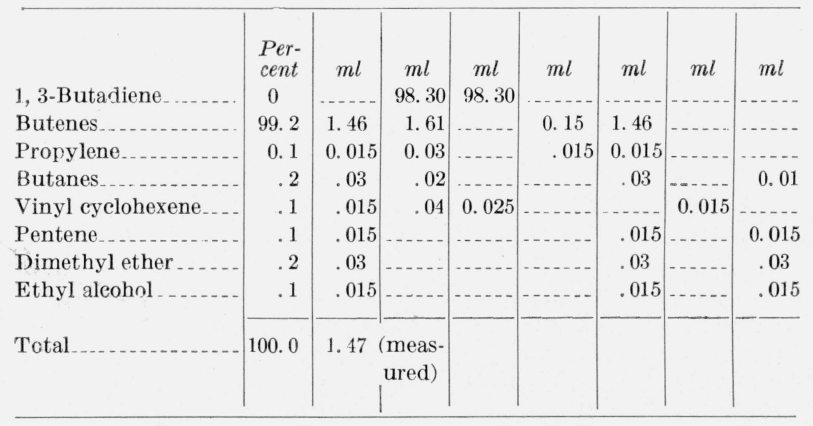

a These values correspond to plus corrections (See text).

${ }_{b}^{b}$ These values correspond to minus corrections (See text).

$c$ These components were not present in the original sample and therefore are of undetermined origin.

Note: If the dimer is not removed from original sample, the Hinckley analysis will be in error (unless corrected), but it cannot be said from the chemical viewpoint that the dimer is "incorrectly retained" by the maleic anhydride.

The balance sheet for each sample may be briefly considered.

In the case of sample 55-15, no significant amount of 1,3-butadiene was found in the residue. A trace of 1,2-butadiene not found in the original sample is reported in the residue-but the amount is not significant. Of the $0.05 \mathrm{ml}$ of propylene found in the sample, $0.04 \mathrm{ml}$ appeared correctly in the residue, leaving $0.01 \mathrm{ml}$ incorrectly retained in the maleic reagent. (Actually, this is not a significant difference but is mentioned to illustrate the method of computing.) Of the $1.48 \mathrm{ml}$ of 1-butene reported in the sample, only $0.70 \mathrm{ml}$ was found in the residue, indicating $0.78 \mathrm{ml}$ as incorrectly retained in the maleic reagent. On the other hand, of the $0.58 \mathrm{ml}$ of 2-butene reported in the sample $1.56 \mathrm{ml}$ bobs up in the residue, an excess of 0.98 , which is listed in column 8 . This picture with respect to the butenes appears out of line. It seems more plausible to consider the butenes as a group rather than individually, and this certainly gives a cleaner analysis. Computed on this basis, there remains $0.20 \mathrm{ml}$ of total butenes in excess of the amount present in the sample. If 2.26 is accepted as a better value for total butenes in the original sample than the 2.06 reported, the corrected value, 97.62, agrees exactly with the value obtained by the freezing point. Continuing as before, only $0.01 \mathrm{ml}$ of the original $0.03 \mathrm{ml}$ of $n$-butane appears in the residue, and no significant amount of the original $0.04 \mathrm{ml}$ of dimer appears in the residue. The latter is, of course, to be expected and should be corrected. Ignoring the butenes as individuals, this leaves a balance of $0.07 \mathrm{ml}$ plus correction and no minus correction. The residue measured was 2.31 ; the correct residue is 2.38 ; and the $1,3-$ butadiene, correspondingly corrected, is 97.62. Thus the freezing point, mass spectrometer, and method L. M. 2.1.1.7 can be brought into extraordinary agreement.

In the case of sample 5-14, a total of $0.32 \mathrm{ml}$ of butenes, propylene, and 1,2-butadiene appears in the residue in excess of the amounts reported for the sample. The original analysis by mass spectrometer gives a corrected value of 97.83 percent of 1,3-butadiene. The volumetric analysis corrected for components incorrectly retained in the maleic anhydride yields the value 97.80. But the freezing point value is 97.98 .

The balance sheet for sample 11-20 gives closer agreement. Corrected for the more modest excess of $0.17 \mathrm{ml}$ of total butenes, the original mass spectrometer value becomes 98.45. The volumetric value, corrected for $0.06 \mathrm{ml}$ incorrectly retained in the maleic reagent, becomes 98.43. The freezing point gave 98.48 .

The results from sample $86-2$ are not so satisfactory. Originally there was fine agreement between the three methods; but a large correction for components incorrectly retained in the maleic reagent lowers the volumetric value to 97.84 . There is also a minor excess of $0.09 \mathrm{ml}$, which lowers the mass spectrometer value to 97.88 . The freezing point remains frozen at 97.99 .

In the case of sample 55-17, the balance sheet shows no significant amount of any compound in the residue not originally present in the sample. Some of the butene fraction originally present did not appear in the residue, and the Hinckley result can thus be corrected from 98.53 to 98.38 percent. The analysis of the original sample by the mass spectrometer was 98.30. There was no measurement of the freezing point. 
The original and corrected data are tabulated in table 2. Columns 2, 3, and 4 give the original values obtained by the freezing point, mass spectrometer, and volumetric (L. M. 2.1.1.7) methods, respectively. Column 5 gives the volumetric value corrected by the mass spectrometer in the manner just described. Column 6 gives the mass spectrometer value corrected by the combined Hinckley-mass spectrometer procedure, also just described.

TABLE 2. Analyses of specification grade 1,3-butadiene by freezing point, mass spectrometer, and Hinckley method

\begin{tabular}{|c|c|c|c|c|c|}
\hline Sample & $\begin{array}{c}\text { Freezing } \\
\text { point }\end{array}$ & $\begin{array}{l}\text { Mass } \\
\text { spec- } \\
\text { trometer }\end{array}$ & $\begin{array}{l}\text { L. M. } \\
2.1 .1 .7\end{array}$ & $\begin{array}{c}\text { L. M. } \\
2.1 .1 .7 \\
\text { corrected } \\
\text { by } \\
\text { Mass } \\
\text { spec- } \\
\text { trometer }\end{array}$ & $\begin{array}{c}\text { Mass } \\
\text { spec- } \\
\text { trometer } \\
\text { corrected } \\
\text { by } \\
\text { Hinckley- } \\
\text { mass } \\
\text { spec- } \\
\text { trometer }\end{array}$ \\
\hline $55-15 \ldots$ & $\begin{array}{r}\text { Percent } \\
97.62\end{array}$ & $\begin{array}{r}\text { Percent } \\
97.82\end{array}$ & $\begin{array}{r}\text { Percent } \\
97.69\end{array}$ & $\begin{array}{r}\text { Percent } \\
97.62\end{array}$ & $\begin{array}{l}\text { Percent } \\
\quad 97.62\end{array}$ \\
\hline $5-14$ & 97.98 & 98.14 & 97.87 & 97.80 & 97.83 \\
\hline $11-20$ & 98.48 & 98.62 & 98.50 & 98.43 & 98.45 \\
\hline $86-2-2$ & 97.99 & 97.97 & 98.02 & 97.84 & 97.88 \\
\hline $55-17$ & None & 98.30 & 98.53 & 98.38 & \\
\hline
\end{tabular}

If we arbitrarily consider differences of less than 0.1 percent as agreements, we find the following such agreements in the first four samples reported:

Original freezing point with original mass spectrometer.

Original freezing point with original L. M.

2.1.1.7

Original mass spectrometer with original L. M. 2.1.1.7

Original freezing point with corrected mass spectrometer

Original freezing point with corrected volumetric

Original mass spectrometer with corrected volumetric

Corrected mass spectrometer with corrected volumetric

These comparisons do not seem to provide sufficient reason for purchasing a Koppers-Hinckley apparatus to correct a mass spectrometer, or a mass spectrometer to correct a Koppers-Hinckley apparatus, or either to correct a freezing point. They do suggest a more realistic attitude with regard to analytical tolerances.

\section{Effect of the Amount of Diamylamine Inhibitor in the Maleic Anhydride}

Amounts of diamylamine varying from 1 to 7 percent have been recommended. The three concentrations favored by various laboratories were tested: 1 percent, 2 percent and 7 percent. The original ampoules of maleic anhydride supplied with the apparatus (supposedly official) contained $50 \mathrm{~g}$ of the reagent. This amount was first used, but afterward it was increased to $65 \mathrm{~g}$ (Hinckley's recommendation). A sample containing approximately 96 percent of 1,3-butadiene was used throughout these measurements. It was selected because it contained 1,2-butadiene and apparently the majority of the "difficult" components (styrene excepted). The sample and residues were analyzed by the mass spectrometer, and these analytical data, together with the analyses by the Hinckley method, are shown in table 3. This table is arranged in the same manner as the previous tabulated balances, except that the volumes (in $\mathrm{ml}$ ) of each component found in the residue appear in a single column. The algebraic signs indicate corrections.

The data show notable amounts of 1,3-butadiene escaping the maleic reagent that contains only 1 percent of diamylamine; and this error was larger with $50 \mathrm{~g}$ of reagent than with $65 \mathrm{~g}$ of reagent. Results with the reagent containing 7 percent of diamylamine are too confused to mean anything. There were large amounts of almost all of the components present in the residue that were not found in the original sample. Check observations yielded the same story, and an analysis of the "blank", or gases collected after this series of analyses and during the subsequent continued passage of carbon dioxide through the reagent, again showed the presence of components not originally in the sample. A long series of analyses yielded no satisfactory reproducibility, and the 7-percent variant was accordingly discarded along with the 1 percent. The reagent with 2 percent of diamylamine did not give a perfect performance, but there were no greatly embarrassing excesses, and the results could be coordinated with those of the mass spectrometer. The Hinckley analysis, corrected by means of the mass spectrometer, gave the result: 95.62 percent conjugated dienesa very satisfactory agreement.

Just how the "inhibitor" functions is not entirely 
known. The analyses indicate that less 1,2-butydiene is retained by the reagent containing 2 percent of the inhibitor than is retained by the 1-percent variant; but the 7-percent valiant yielded no 1,2-butadiene to the residue. Instead, an embarrassing increase in both butanes and butenes is noted. Whatever the chemical picture, it seems that the change in surface tension of the maleic solution with addition of the diamylamine inhibitor results in the formation of smaller bubbles of ascending gas and that the 2-percent variant is more suitable in this respect than the 1 percent. Herein may lie its real contribution.

Other analyses reported herein, including those of section $\mathrm{V}, 1$, were done with $65 \mathrm{~g}$ of the maleic anhydride containing 2 percent of diamylamine.

TABLE 3. Effect of the diamylamine inhibitor

\begin{tabular}{|c|c|c|c|c|c|c|c|c|c|c|c|}
\hline \multirow[b]{2}{*}{ Component } & \multirow{2}{*}{$\begin{array}{c}\text { Composi- } \\
\text { tion of } \\
\text { original } \\
\text { sample } \\
\text { by mass } \\
\text { spectrom- } \\
\text { eter }\end{array}$} & \multicolumn{3}{|c|}{$\begin{array}{l}\text { Results with } 1 \text { percent inhibitor } \\
50 \mathrm{~g} \text { of reagent }\end{array}$} & \multicolumn{3}{|c|}{$\begin{array}{l}\text { Results with } 1 \text { percent inhibitor } \\
6.5 \mathrm{~g} \text { of reagent }\end{array}$} & \multicolumn{2}{|c|}{$\begin{array}{l}\text { Results with } 2 \text { per- } \\
\text { cent inhibitor } 65 \\
\text { g of reagent }\end{array}$} & \multicolumn{2}{|c|}{$\begin{array}{l}\text { Resuits with } 7 \text { per- } \\
\text { cent inhibitor } 65 \\
\text { g of reagent }\end{array}$} \\
\hline & & $\begin{array}{l}\text { Hinckley } \\
\text { analysis } \\
\text { of origi- } \\
\text { nal } \\
\text { sample }\end{array}$ & $\begin{array}{l}\text { Analysis } \\
\text { of residue } \\
\text { by mass } \\
\text { spectrom- } \\
\text { eter }\end{array}$ & $\begin{array}{l}\text { Amount } \\
\text { of com- } \\
\text { ponent in } \\
\text { residue }\end{array}$ & $\begin{array}{l}\text { Hinckley } \\
\text { analysis } \\
\text { of origi- } \\
\text { nal } \\
\text { sample }\end{array}$ & $\begin{array}{c}\text { Analysis } \\
\text { of residue } \\
\text { by mass } \\
\text { spectrom- } \\
\text { eter }\end{array}$ & $\begin{array}{l}\text { Amount } \\
\text { of com- } \\
\text { ponent in } \\
\text { residue }\end{array}$ & $\begin{array}{c}\text { Analysis } \\
\text { of residue } \\
\text { by mass } \\
\text { spectrom- } \\
\text { eter }\end{array}$ & $\begin{array}{l}\text { Amount } \\
\text { of com- } \\
\text { ponent in } \\
\text { residue }\end{array}$ & $\begin{array}{l}\text { Analysis } \\
\text { of residue } \\
\text { by mass } \\
\text { spectrom- } \\
\text { eter }\end{array}$ & $\begin{array}{l}\text { Amount } \\
\text { of com- } \\
\text { ponent } \\
\text { residue }\end{array}$ \\
\hline 1,3-Butadiene... & $\begin{array}{l}\text { Percent } \\
95.60\end{array}$ & $\begin{array}{l}\text { Percent } \\
96.40\end{array}$ & $\begin{array}{r}\text { Percent } \\
10.0\end{array}$ & $\begin{array}{c}m l \\
\mathrm{a}-0.36\end{array}$ & $\begin{array}{l}\text { Percent } \\
\quad 96.35\end{array}$ & $\begin{array}{r}\text { Percent } \\
4.6\end{array}$ & $\begin{array}{c}m l \\
\mathrm{a}-0.17\end{array}$ & $\begin{array}{r}\text { Percent } \\
0.1\end{array}$ & $m l$ & $\begin{array}{l}\text { Perceni } \\
\quad 0.2\end{array}$ & $\begin{array}{l}m l \\
-0.02\end{array}$ \\
\hline 1,2-Butadiene. - & 1. 11 & & 9. 0 & $\mathrm{~b}+.32$ & & 14. 3 & $\mathrm{~b}+.52$ & 16. 1 & b +0.59 & (2) & ........ \\
\hline Propadiene.......... & 0.18 & & 8.6 & c. 31 & & 3.1 & $\mathrm{a}-.11$ & 3.7 & $\mathrm{a}-.14$ & 0.5 & -0.05 \\
\hline Propylene & .08 & $\ldots-$ & 1.7 & +.06 & & 1.8 & $\mathrm{~b}+.07$ & 1.8 & $\mathrm{~b}+.07$ & 1. 6 & c. 17 \\
\hline Propane & $\ldots$ & & (n) & . & & . & & & & & ....... \\
\hline 1-Butene....... & 2.24 & & 53.0 & $\mathrm{~b}+1.91$ & & 63.5 & '2. 32 & 57.9 & $b+2.14$ & 35.5 & с3. 68 \\
\hline 2-Butene & 0.68 & & 17.0 & $\mathrm{~b}+0.61$ & & 12.0 & +.44 & 18.5 & 0.69 & 32.1 & e 3.33 \\
\hline n-Butane & .08 & & 0.5 & $\mathrm{~b}+.02$ & & 0.5 & +.02 & 0.5 & $\mathrm{~b}+.02$ & 24.0 & '2. 49 \\
\hline$i$-Butane ....... & & & .... & & & & & & & 4. 9 & c 0.51 \\
\hline Pentadiene........... & & $\ldots$ & 0.01 & & & 0.02 & & 0.02 & & $\ldots$ & ...... \\
\hline Pentenes . . . . & & $\ldots$ & .1 & & & .1 & & 1.1 & $\mathrm{~b}+0.04$ & 4. 9 & с 0.51 \\
\hline Pentanes ... . . . . & & & 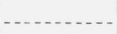 & & & $\ldots$ & & - . . . & 1 & 0.6 & с. 06 \\
\hline Vinylcyclohexene & & & & & & .1 & & 0.4 & .01 & .1 & .... \\
\hline
\end{tabular}

a Should not have been in the residue.

b All of the component should have been delivered to the residue, but the amount represented by the difference between the total originally present and hat found in the residue was incorrectly retained in the absorption system.

- More of the component was found in the residue than was found in the origina! sample. (The excess is the difference between the two.)

\section{Effect of Rate of Flow of the Sample Through the Maleic Absorber}

The rate of flow specified is 35 cc of carbon dioxide sweeping gas per minute. Four rates were tried: $10,35,80$, and $100 \mathrm{cc} /$ minute. Analyses of the residue by the mass spectrometer are tabulated below:

TABLE 4. Effect of rate of flow of sweeping gas

\begin{tabular}{|c|c|c|c|c|c|}
\hline \multirow[b]{2}{*}{ Component } & \multirow[b]{2}{*}{$\begin{array}{l}\text { Original } \\
\text { sample }\end{array}$} & \multicolumn{4}{|c|}{ Residue } \\
\hline & & $\begin{array}{l}\text { Flow, } \\
10 \mathrm{cc} / \\
\text { min }\end{array}$ & $\begin{array}{l}\text { Flow, } \\
35 \mathrm{cc} / \\
\text { min }\end{array}$ & $\begin{array}{l}\text { Flow, } \\
80 \mathrm{ce} / \\
\text { min }\end{array}$ & $\begin{array}{l}\text { Flow, } \\
100 \mathrm{cc} / \\
\text { min }\end{array}$ \\
\hline 1,3-Butadiene . - & $\begin{array}{r}\text { Percent } \\
95.60\end{array}$ & $\begin{array}{r}\text { Percent } \\
0.1\end{array}$ & $\begin{array}{r}\text { Percent } \\
0.1\end{array}$ & $\begin{array}{r}\text { Percent } \\
0.1\end{array}$ & $\begin{array}{r}\text { Percent } \\
0.1\end{array}$ \\
\hline 1,2-Butadiene.. & 1.11 & 16.2 & 13.9 & 15.6 & 16. 2 \\
\hline Propadiene_.... & 0.18 & 3.7 & 6.7 & 6.0 & 6.6 \\
\hline Propylene..... & .08 & 1.8 & 2.1 & 1.5 & 1.2 \\
\hline 1-Butene.......... & 2.24 & 58.4 & 60.4 & 59.6 & 58.3 \\
\hline 2-Butene ........ & 0.68 & 18.7 & 16.0 & 16.4 & 16.9 \\
\hline$n$-Butane & .08 & 0.5 & 0.6 & 0.6 & 0.5 \\
\hline Pentenes & ..... & .1 & .2 & 1 & .2 \\
\hline Pentadiene........... & $\ldots$ & .02 & $\ldots$ & .1 & $\ldots$ \\
\hline Vinylcyclohexene... & $\ldots$ & .4 & 0.2 & .1 & 0.1 \\
\hline
\end{tabular}

From these data it may be concluded that $35 \mathrm{cc}$ per minute is a very safe rate for the sweeping gas. Indeed, were it not for the fact that fritted disks such as are used to break up the gas stream entering the absorber vary somewhat in their performance, it would be well to increase the recommended rate and so shorten the time required for a determination. (An analysis at the $10 \mathrm{cc} / \mathrm{min}$ rate required over an hour; that at the recommended $30 \mathrm{cc} / \mathrm{min}$ required 22 minutes; but the one made at $80 \mathrm{cc} / \mathrm{min}$ took only 10 minutes). However, the safe rate should be determined for each fritted disk used if any departure from the instructions is contemplated.

\section{Accuracy and Reproducibility}

The accuracy obtained in analyzing specification-grade butadiene can be estimated by comparison with the results obtained by the mass spectrometer and the freezing-point method. These have been previously noted (table 1) and 
indicate that a value \pm 0.2 percent of the whole may be expected. No good estimation of accuracy can be made for samples of lesser purity.

When the apparatus is operating correctly, the reproducibility to be expected with each type of sample may be given as follows:

\begin{tabular}{|c|c|}
\hline Conjugated dienes & $\begin{array}{c}\text { Approximate reproduci- } \\
\text { bility (percent by } \\
\text { volume of the whole) }\end{array}$ \\
\hline Percent & \pm 0.01 \\
98.5 or better & \pm 0.02 to $\pm 0.2{ }^{4}$ \\
85 to 95 & \pm 0.4 \\
2 to 15 & \\
\hline
\end{tabular}

${ }_{4}^{4}$ Depending upon the composition with respect to $\mathrm{C}_{5}$ and $\mathrm{C}_{8}$ hydrocarbons hat may interfere with the reaction.

Typical anslyses illustrating the attainable reproducibility have already been given in previous sections of this report. Others follow to supplement the range of composition not previously covered.

TABLE 5. Analyses illustrating attainable reproducibility

\begin{tabular}{|c|c|c|c|}
\hline Condition & Lot a & $\begin{array}{c}\text { Conjugated } \\
\text { dienes }\end{array}$ & Analyst \\
\hline \multicolumn{4}{|c|}{ SAMPLE $55-15$} \\
\hline \multirow{4}{*}{ Not dried.- } & & $\begin{array}{l}\text { Percent by } \\
\text { volume }\end{array}$ & \\
\hline & $\mathrm{B}$ & 97. 67 & MS. \\
\hline & $\mathrm{B}$ & 97.68 & MS. \\
\hline & B & 97.68 & MS. \\
\hline \multirow{9}{*}{ Dried over indicating drierite... } & A & 97.68 & RLT. \\
\hline & $\mathrm{C}$ & 97.67 & RLT. \\
\hline & $\mathrm{C}$ & 97.68 & RLT. \\
\hline & $\mathrm{C}$ & 97.68 & RLT. \\
\hline & $\mathrm{C}$ & 97.70 & RLT. \\
\hline & $\mathrm{D}$ & 97. 70 & MS. \\
\hline & $\mathrm{D}$ & 97. 70 & MS. \\
\hline & $\mathrm{D}$ & 97.70 & MS. \\
\hline & $\mathrm{D}$ & 97.70 & MS. \\
\hline \multirow{2}{*}{\multicolumn{2}{|c|}{$\begin{array}{l}\text { Average } \\
\text { A verage deviation from average }\end{array}$}} & 97.69 & \\
\hline & & \pm 0.01 & \\
\hline
\end{tabular}

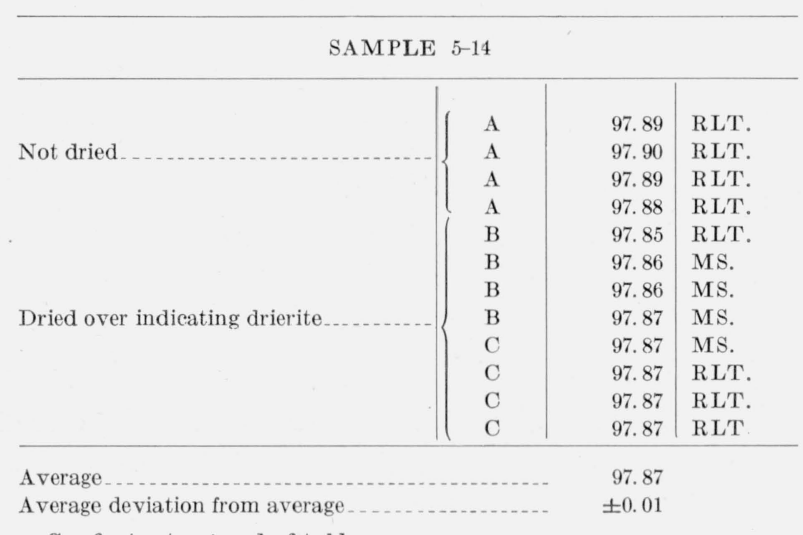

See footnote at end of table.
TABLE 5. Analyses illustrating attainable reproducibilityContinued

\begin{tabular}{l|c|c}
\hline \hline Condition & Lot a & $\begin{array}{c}\text { Conjugated } \\
\text { dienes }\end{array}$ \\
\hline
\end{tabular}

SAMPLE $\quad 11-20$

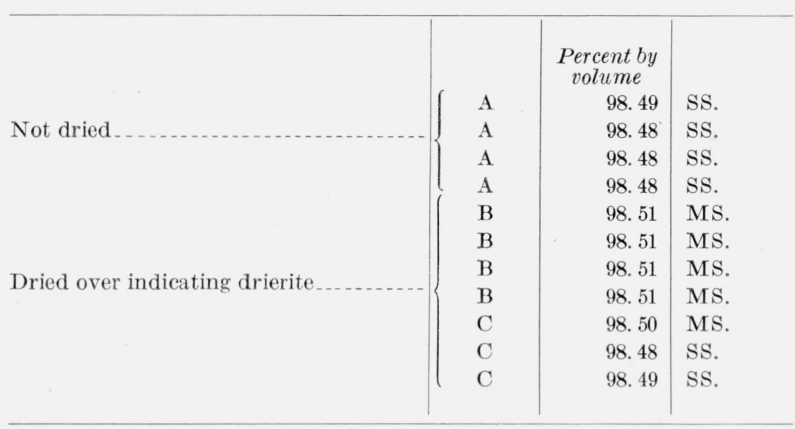

A verage _. . . . 58.50

A verage deviation from average _............... $\quad \pm 0.01$

SAMPLE $86-2$

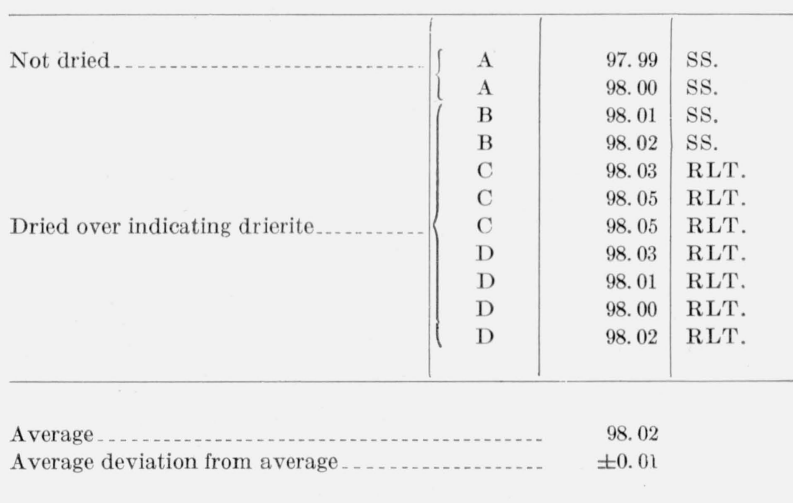

SAMPLE $43-3$

Not dried..... $\mid$\begin{tabular}{l|l|l|l}
\hline A & 15.1 & MS. \\
A & 14.9 & MS. \\
A & 14.9 & RLT. \\
A & 14.7 & RLT. \\
\hline
\end{tabular}

A verage . _ _ _ _ 14.9

Average deviation from average ............... $\quad \pm 0.1$

Not dried ................. $\mid$\begin{tabular}{l|l|l} 
B & 14.0 & RLT. \\
B & 14.0 & RLT. \\
B & 14.0 & RLT. \\
B & 13.9 & RLT.
\end{tabular}

Average - .

Average deviation from average ............. \pm 0.03

See footnote at end of table. 
TABLE 5. Analyses illustrating attainable reproducibilityContinued

\begin{tabular}{l|c|c}
\hline \hline Condition & Lot a & $\begin{array}{c}\text { Conjugated } \\
\text { dienes }\end{array}$ \\
\hline
\end{tabular}

SAMPLE $43-3$

Not dried........ $\mid$\begin{tabular}{l|r|l}
\hline & $\begin{array}{c}\text { Percent by } \\
\text { volume }\end{array}$ & \\
$\mathrm{C}$ & 15.0 & RLT. \\
$\mathrm{C}$ & 14.9 & RLT. \\
$\mathrm{C}$ & 14.5 & RLT. \\
$\mathrm{C}$ & 14.2 & RLT. \\
\hline
\end{tabular}

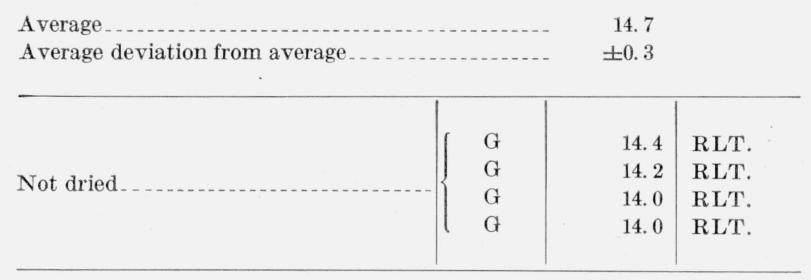

$\begin{array}{ll}\text { Average } & 14.2 \\ \text { A verage deviation from average } \ldots \ldots \ldots & \pm 0.2\end{array}$

$|\quad|$\begin{tabular}{l|l|l}
\hline Not dried. & & \\
15.2 & RLT. \\
14.7 & RLT. \\
14.8 & RLT. \\
14.4 & RLT. \\
14.4 & RLT. \\
15.6 & RLT. \\
15.3 & RLT. \\
\hline
\end{tabular}

$\begin{array}{lr}\text { Average } & 14.9 \\ \text { Average deviation from average } & \pm 0.4\end{array}$

SAMPLE PL-152-11

Not dried ..... $\mid$\begin{tabular}{l|l|l}
\hline A & 1.3 & RLT. \\
A & 1.8 & RLT. \\
A & 2.0 & RLT. \\
A & 1.6 & RLT \\
A & 1.4 & RLT. \\
\hline
\end{tabular}

Average _.

Average deviation from average . . .

\footnotetext{
a When the sample number is followed by a letter, the sample was taken into the Hinckley sampler, and samples with the same letter are of the same composition. Thus, the lettered samples give a measure of the reproducibility of the analytical procedure. Samples identified by number only are drawn individually from the cylinder into the measuring pipette of the apparatus. Thus, any change in composition upon sampling which intrudes into the analytical picture may be estimated by comparing groups of different letters, or samples identified by number only, once the reproducibility of the analytical method is measured.
}

\section{Notes on the Operating Character- istics of the Koppers-Hinckley-Podbiel- niak Apparatus}

\section{Occasional Erratic Behavior}

Even the best of all possible apparatus will sometimes indulge in the perversity practiced by inanimate objects, and the present apparatus is no exception. The following experiment, which started as a series of analyses, to illustrate the vagaries of sampling, disclosed more than was originally intended. The initial conditions were as listed below.

The apparatus was working correctly in all visible respects. The maleic reagent had been used for nine analyses, (five of a sample containing about 2 percent of conjugated dienes and four of a sample containing about 96 percent of conjugated dienes,) and had given reproducible results in both cases. A fresh solution of potassium hydroxide had been put into the absorber burette. A blank had been obtained. The analysis of sample BB-574, Phillips Hydro-carbon Mixture No. 6, was then undertaken. The cylinder was connected to the measuring pipette of the apparatus by means of a 120-degree stopcock and nitrometer tubing. This arrangement permitted flushing the sampling line with mercury from the pipette and with gas from the cylinder.

This is what happened:

1. With the cylinder vertical, valve at top, and sampling from the vapor phase, 6 analyses yielded the values

\begin{tabular}{|c|}
\hline Conjugated dienes \\
\hline Percent \\
82.56 \\
82.17 \\
82.68 \\
83.25 \\
83.29 \\
83.12 \\
Avg $-82.85 \pm 0.4$ \\
\hline
\end{tabular}

2. The position of the cylinder was then reversed, and with valve at bottom "sampling 
from the liquid phase," 9 analyses yield the values

\begin{tabular}{|c|}
\hline Conjugated dienes \\
\hline Percent \\
82.80 \\
83.60 \\
83.48 \\
83.52 \\
81.75 \\
81.44 \\
82.98 \\
82.73 \\
80.57 \\
Avg $82.54 \pm 0.2$ \\
\end{tabular}

3. A sample was then drawn from the inverted cylinder into the Hinckley sampler, so that four analyses of the same mixture could be made. These analyses yield the values

\begin{tabular}{|c|}
\hline Conjugated dienes \\
\hline Percent \\
80.76 \\
82.35 \\
82.33 \\
84.72 \\
Avg - $82.54 \pm 1.09$ \\
\hline
\end{tabular}

These results are worth a moment's reflection. Series 1 was not expected to check series 2, although closer agreement was expected within each series. Series 3 was then made to show whether the divergence of individual results was caused by sampling or by the performance of the analytical apparatus. Apparently the divergence could not be blamed upon sampling, for series 3 indicated that the apparatus was not yielding reproducible results. The cause was not apparent. Operation was normal in all respects except that the normal operating back pressure had increased from 7 to 9 psi, which is well within the limit set by the mercury relief seal. The joints were examined and appeared to be well lubricated. They were wiggled about with no apparent change. The joints were then tested for leaks by soap solution, and no leaks were detected. These tests were repeated several times, and nothing was found out of order.
The solution of potassium hydroxide was replaced, and during the run for a blank the back pressure suddenly rose to the point of blowing the relief seal. The joints were disconnected and all lines found free, but the maleic-filled absorber was plugged. The maleic reagent could not be withdrawn from the bottom of the absorber even when vacuum was applied. It was withdrawn from the top, and a solid plug below the sintered plate was removed by dissolving in acetone. The absorber was cleaned with acetone, dried by a current of air, and a fresh charge of the maleic reagent put into it. The lines were again connected, a blank was obtained, and analyses of the same sample resumed. This time the following results were obtained:

4. With the inverted cylinder (valve at bottom) three separate lots were taken into the Hinckley sampler. These analyses yielded the values

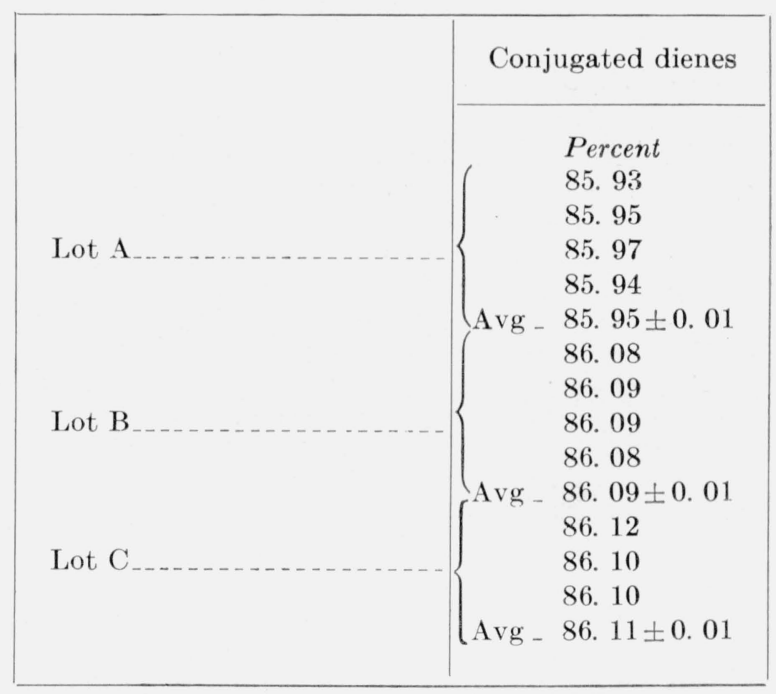

5. With the cylinder inverted and connected as before to the measuring pipette, so that each sample was individually drawn from the cylinder, these values were obtained:

\begin{tabular}{|c|}
\hline Conjugated dienes \\
\hline Percent \\
86.08 \\
86.28 \\
86.38 \\
86.98 \\
86.07 \\
Avg_. $86.16 \pm 0.14$ \\
\hline
\end{tabular}


6. The balance of the sample from lot $\mathrm{C}$ was then analyzed. (The Hinckley sampler had been filled under slight pressure in order to yield a sufficient amount for six analyses). The values obtained were:

\begin{tabular}{|c|}
\hline Conjugated dienes \\
\hline Percent \\
86.10 \\
86.14 \\
86.09 \\
Avg_- $86.11 \pm 0.02$ \\
\hline
\end{tabular}

7. The inverted cylinder was again connected to the apparatus directly, and a series of individual samples were withdrawn and analyzed. The values yielded were:

\begin{tabular}{|c|}
\hline Conjugated dienes \\
\hline Percent \\
86.13 \\
86.15 \\
86.33 \\
86.28 \\
86.10 \\
86.08 \\
86.09 \\
86.07 \\
86.07 \\
86.06 \\
86.07 \\
$86.13 \pm 0.07$ \\
\hline
\end{tabular}

The results of series 4 to 7 , inclusive, may now be compared. Series 4 shows the apparatus giving a pleasing reproducibility. The individual results of each lot, A, B, and C, are in excellent agreement with themselves. Lot A differs from the other two by 0.15 percent, and this difference may be tentatively assigned to the vagary of the sampling procedure. The following series 5 was intended to estimate the extent of chance change of composition during sampling. Differences were found, the largest variation being 0.4 percent. Series 6 was designed to tie back to series 4 , to show that the analytical apparatus was still performing in a trustworthy manner. Since series 6 , lot C, came from the same sampler as series 4 , lot $\mathrm{C}$, the apparatus was yielding consistent re- sults. Therefore, the divergence observed in series 5 may be tentatively assigned to the vagary of the sampling procedure. Series 7 was designed to explore this vagary further. The procedures used were the same as employed for series 5 . The analyses in this series show both divergence and close agreement depending on the part of the list selected.

Although the data obtained indicate that sampling is erratic (a subject to be mentioned briefly at the end of this report), the immediate problem is with respect to the erratic behavior of the Koppers-Hinckley-Podbielniak apparatus itself. Except for a difference of 2 psi in operating pressure, which was not at first considered significant, there was no outward or visible difference in operation of the analytical apparatus throughout the entire series, 1 to 7 inclusive. There was no reason for the analyst to believe that the apparatus was not giving good results at first, except that the results themselves were not as consistent as he supposed they should be. Until series 3, there was no positive evidence that the apparatus was giving poor analyses. Except for the change in back pressure, the actual operating characteristics, in so far as one could perceive, were the same for both series 3 and 4 . Series 5 complicates the problem by introducing a different order of reproducibility than that obtained by each individual lot of series 4. Faced with such data, the analyst does not know how to measure the performance of the apparatus even in terms of reproducibility of the results obtained, unless he always uses the Hinckley sampler and performs many analyses for each sample examined. His problem, then, becomes essentially one of finding the time to do a decent analysis of all samples submitted to him.

The importance of employing a sample container capable of delivering at least five successive portions of the same composition for analysis cannot be too greatly stressed. The foregoing experiment shows that the performance of the apparatus with respect to reproducibility cannot be measured otherwise, and that this performance must be measured if the operator is to have any assurance of just where he is.

Further experience with the apparatus indicated that an increasing back-pressure was often accompanied by poor reproducibility. If the restriction occurred in the maleic-filled absorber, this was always the case. Evidently the reagent is spoiled 
by excessive water vapor or some of the heavier hydrocarbons. This may happen frequently, and when it does the warning of the pressure gage is usually the only indication of trouble, for the appearance of the reagent is not enough for a diagnosis. In itself, this warning is inadequate. Hence, an actual measure of reproducibility must be retained. Unfortunately there seems to be no tendency on the part of RuR users to hold to this essential.

\section{Introduction of the Sample into the Apparatus}

Since there are two methods for introducing the sample they should be considered separately.

(1) The first method (which we greatly prefer) involves the use of the special sampling tube supplied with the apparatus. This tube is connected to the mercury sump of the apparatus by means of an interchangeable grinding. Interposed between the female grinding sealed to the sump and the male grinding sealed to the sample tube is a male-female grinding drilled with appropriate holes. The intermediate grinding may be rotated with respect to either of the other two, and the grinding on the sampling tube may be rotated with respect to the intermediate grinding. All of the necessary connections can thus be achieved.

This system is not conventional and is therefore mildly confusing at first glance. The written explanation of its operation, while perfectly clear, is apt to leave one's eyes and hands in some doubt during the initial experience. Actually, the system is perfectly simple, and its operation is easy enough. It could be taught, by demonstration, to nontechnical personnel.

After going through the necessary motions two or three times, the operation of this sampler is not only simple, but it offers a convenient service. Where there is any doubt about change of composition on sampling from a cylinder under pressure - and this doubt must always exist for many types of samples until it can be demonstrated that separation does not occur with each type of sample-the sampler can be used to establish reproducibility to the extent of four to six samples of the same composition. Thus it may be possible to withdraw one lot of say four samples from a cylinder, make four determinations in good agreement, and then withdraw a second lot of four samples whose analyses are again in agreement with themselves but not necessarily in agreement with the first lot.

The Hinckley sampler may be used in three ways:

1. If it can be flushed with sample and thereafter connected to the apparatus, the procedure is simple enough. However, specific directions should be given to insure complete flushing and such directions would involve a measurement of displacing gas in terms of volume or of time at a measured rate of flow. The latter combination is preferable since it fixes at least vaguely the reproducibility of the sampling.

2. It can be filled with mercury which the sample will later displace. (In this event, a 120-degree cock should be connected to the inlet to permit flushing of the sampling line with mercury from the sampler and with gas from the cylinder or source of sample, and a tee should be connected to a mercury seal of somewhat over barometric height.)

3. It can be evacuated prior to filling with sample. In case this is done, the sample should be supplied at such a rate that no excessively reduced pressure occurs in the sampling line.

The second method of sampling is to connect the source directly to the apparatus with the sampler displaced by a stopcock key. Again the 120degree cock appended to the system will permit flushing the sampling line first with mercury from the apparatus and then with sample from its source. This cock amounts to a necessity in so far as we are concerned. The operations are simple. The procedure of sampling directly into the apparatus is poor, since a separation of the sample en route to the apparatus may alter its composition.

\section{Venting}

When the sample for analysis has been transferred from the Hinckley sampler under some pressure to the measuring pipette, a necessary step in the actual measurement of this sample is to turn the sampler to connect the pipette to the mercury sump, which is vented to the atmosphere through a small hole at the front of the sump. If the three bores involved become plugged with lubricant when the grindings are turned to make the necessary connections, the amount of sample is not known. A slightly generous use of the very viscous lubricant sup- 
plied with this apparatus, combined with the pressure exerted downward by the weight of mercury within the sampler (which tends to cause the lubricant to exude), has actually produced plugs of lubricant that interfere with measurement of the sample. When this happens, there is no decisive way of knowing it. Usually when the sample is properly vented, there are one or more indications that venting has actually occurred: a bead of mercury may be blown from the bores; the rush of excess sample into the sump is audible; the presence of excess sample in the atmosphere can be detected by its distressing odor. Sometimes no one of these three portents are perceived. A side tube projecting from the vent hole, to which is affixed a short length of smallish diameter rubber tubing terminating in a short length of glass tube which dips just under the surface of the water in the jacket surrounding the measuring pipette, is very helpful. Then, if excess pressure is relieved, it is positively indicated by escaping bubbles. If no bubbles appear, the operator knows that the connection is plugged; or if water is drawn into the tube, the operator knows that excess pressure was never achieved upon drawing the sample into the measuring pipette. (This has happened when the mercury levels in the leveling bulbs belie the fact.)

Errors caused by failure to vent are interesting, because they can travel to the right or left of center (speaking graphically). Thus, if excess pressure is not vented to atmosphere the sample will be too large by an indeterminate amount, the consequent residue too large, and the corresponding purity too low. But if excess pressure has not been achieved in sampling, one of four conditions may be obtained.

1. If the bores are plugged, the sample is too small by an indeterminate amount and the purity is correspondingly too high.

2 . If the bore is not plugged and the sump happens to be filled with air when the pipette is connected thereto, the residue will be too large by the amount of air drawn into the pipette, and the purity correspondingly too low.

3. If the bore is not plugged and the sump is filled essentially with carbon dioxide, which represents the usual operating condition after the first analysis for the day, the sample will be diluted with carbon dioxide and will be correspondingly too small, with a purity correspondingly too high.
4. Finally, if the sump is filled with carbon dioxide that contains any appreciable amount of the previous sample, the purity obtained may be either high or low, depending upon the proportion of sample in the sump and its composition with respect to the composition of the sample to be analyzed.

The connection to the water bath could eliminate these uncertainties.

\section{Detection of Leaks}

The instruction manual supplied with this apparatus states: "Leaks will be troublesome unless great care is taken to have a tight system. Careful greasing of stopcocks and joints and tight connections are necessary." This is quite true.

There are two procedures ordinarily used to detect and guard against leaks. The first, and perhaps the most generally used, procedure is based upon the optimistic assumption that there are no leaks. When this procedure is used, leaks are detected by inductive reasoning. Thus the analyst may proceed from result to result until it becomes apparent that results do not check and he suspects, finally, that something has happened to the apparatus. For the present this procedure is presumably to be used with method L. M. 2.1.1.7. To a certain extent, this is inescapable, for leaks may occur at any time during the course of any analysis. At any rate, once the leak is suspected it should be detected and repaired and not simply repaired by completely reassembling the apparatus in the hope that this time it went together tightly.

The second procedure is to test for leakage prior to use, during use, and after use, if anything important is involved. This assumes that if the analysis is done at all there was some good reason for it. This procedure has so much to recommend it to those who want correct answers that it in turn is strongly recommended for inclusion in L. M. 2.1.1.7. The question, then, is what test or tests can be employed?

If the apparatus is assembled without reagents, pressure can be applied to unbalance the mercury seal between the KOH-filled absorber and the outlet of the maleic-filled absorber. A return of the mercury up the capillary tube then indicates leakage. But to apply this test, the apparatus must be dry and free of reagent. The test is according- 
ly costly in time and effort and is hardly the thing to use during a series of analyses.

With the maleic reagent in the absorber no leak test based upon a change in pressure seems possible, since notable interference may be expected from absorption or desorption. A bypass across the maleic absorber would permit testing of the glass-to-metal spherical joints, which are the most apt to give trouble. Certainly a suitable leak test should be devised for use during actual operation, or for use between analyses with all reagents in place. And this test should be made with the apparatus under operating pressure, not under reduced pressure.

\section{Mercury Hazard}

The Koppers-Hinckley-Podbielniak apparatus presents a potential mercury hazard. The air about the apparatus was examined with Woodson's optical mercury vapor detector (a General Electric instrument). Normal operation will usually deposit enough mercury on the various heated surfaces of the Koppers-Hinckley-Podbielniak unit to furnish concentrations of mercury vapor in air around the apparatus greater than $250 \mu \mathrm{g} / \mathrm{m}^{3}$. The allowable limit, according to the National Institute of Health, is $100 \mu \mathrm{g} / \mathrm{m}^{3}$. Notable amounts of mercury have been found excreted in the urine of several workers exposed to $20 \mu \mathrm{g} / \mathrm{m}^{3}$. When the heated surface of the Koppers-Hinckley-Podbielniak apparatus were cleaned and mercury kept from them, the concentration eventually dropped to about $50 \mu \mathrm{g} / \mathrm{m}^{3}$. However, the cleaned surfaces do not represent average laboratory conditions. The apparatus cannot be operated without occasionally depositing some mercury on the hot spots.

\section{Notes on Sampling}

It has long been known that special procedures are required to capture a true sample of the confined liquid phase of a two (or more) component system boiling below atmospheric temperature at existing atmospheric pressure (and not azeotropic). The procedures may be outlined:

1. The liquid phase is made homogeneous.

2. A sufficient portion of the liquid phase is isolated from the bulk of the mixture, without a change of composition of the mixture and hence without boiling.

3. This isolated portion of the liquid phase is completely evaporated into a suitable container, again without change of composition.

4. The resulting vapor is made homogeneous.

It is of course perfectly obvious that the composition of the vapor above the liquid does not represent the composition of the liquid, and that it is constantly changing over the course of the evaporation of the liquid. It has also been found that significant changes of composition occur when the liquid itself is removed through a tube that remains open to the bulk of the liquid during the process of sampling. Thus the composition of a sample of liquid removed by withdrawing into a capillary tube depends upon the rate of sampling, the bore of the tube, and even the material of the tube, as well as the ordinary conditions of temperature, pressure, and composition of the liquid.

If sampling occurs from a closed system in which the liquid is under pressure, notable separation is sometimes achieved. Such separation is astonishingly large for systems such as nitrogen-methane, which occurs in helium stills, and the behavior of this mixture has served to magnify the effect to be expected in the butadiene mixtures. Withdrawal "from the liquid phase" of an inverted cylinder is always accomplished at the cost of some degree of separation at the valve. Whether or not this is significant must be determined before any reliance can be placed in any analytical data from any source. From such observations as have been made in connection with this study, it would seem reasonable not to worry too much about separation of the specification grades. Undoubtedly it occurs, but as a matter of ariithmetic it does not matter. However, the worry is apparent when the "purity" of the sample has been dropped to 85 percent, as was the case with sample P-6.

Until the sample containers themselves are equipped with a suitable device for isolating a true sample of the liquid, much time will be lost in a fruitless comparison of analytical results from various laboratories.

Washington, July 25, 1947. 